\title{
La biblioteca Hurtado de Mendoza y los quijotes de Órgiva
}

La Biblioteca Pública Municipal Hurtado de Mendoza de Órgiva, ubicada en el corazón de la Alpujarra granadina, en el valle del río Guadalfeo, nació oficialmente por Orden Ministerial de 5 de diciembre de 1956.

En la actualidad su colección consta de 23453 volúmenes y está organizada en distintas secciones. En la sección local se puede encontrar bibliografía de toda la Alpujarra, de nuestro municipio, de todas las materias relacionadas con Andalucía en general y de sus ocho provincias en concreto, destacando entre ellas Granada. Disponemos de una amplia colección de temas alpujarreños, historia, arqueología, guías, artesanía, naturaleza, fiestas, agricultura, costumbres leyendas y tradiciones, etc.

En Órgiva residen más de un millar de personas de 39 nacionalidades, y la mayoría hacen uso de la biblioteca. Los servicios que ésta presta son más o menos los del resto de las bibliotecas andaluzas, pero lo que realmente hace única y original a esta biblioteca es el "Aula Cervantina Agustín Martín Zaragoza", inaugurada en el año 2001, Ilena de sorpresas y maravillas con el Ingenioso hidalgo manchego como protagonista absoluto. La colección fue iniciada en 1967 por el bibliotecario de entonces, Agustín Martín Zaragoza, entusiasta del Quijote, que recibió la donación del primer ejemplar por parte del entonces Príncipe de Asturias.

En la sala se expone, en vitrinas, armarios, mesas y estanterías, una colección sorprendente y maravillosa de ediciones del más notable de los libros escritos por Miguel de Cervantes. Las más distintas formas de El ingenioso hidalgo Don Quijote de la Mancha tienen aquí cabida y acomodo y son fuente de información o sorpresa para los investigadores o curiosos que la visiten. El total supera las 150 ediciones y los más de 600 volúmenes de crítica e interpretación: ensayo, biografías del autor, etc.

Destacan entre los fondos de la colección, la primera traducción que en 1865 se hizo al danés, o la edición en esperanto, de 1977 y titulada Ingenia hidalgo don Ouijote de la Mancha. De 1892 hay una edición en papel de hilo, con caracteres en letra bastarda española, publicada en Barcelona en la imprenta de C. Corhs. Más moderna es la publicada en México en lengua quechua que se tradujo en 2005 para conmemorar el IV centenario, o la traducción colombiana del Quijote "a lo paisa".

De 1947 es la publicada en Braille, edición especial para conmemorar el cuarto centenario del nacimiento de Cervantes, en 14 volúmenes y dirigida por Julio Osuna Fajardo. Se encuentran también ediciones en todas las lenguas cooficiales del Estado: vasco, catalán y gallego; así como ejemplares en persa (el enviado por el Sha de Persia), hebreo, ruso, hindi, serbio, árabe, japonés, coreano, etc., hasta un total de 51 idiomas.

Hay ediciones antiguas y valiosas. De la primera edición, de 1605, de Juan de la Cuesta, existe un facsímil, así como de la de 1732 de Argamasilla de Alba, la realizada en 1780 por Joaquín Ibarra o la que hizo en 1917 la Real Academia Española con las planchas de Juan de la Cuesta.

Algunas destacan por su belleza y/o peculiaridad de sus ilustraciones, como la de 1898, con reproducciones de cuadros de José Moreno Carbonero, o la forma tan particular de ilustrar el Quijote de Daniel Urrabieta Vierge, y una de las últimas en incorporarse a la colección ilustrada por el alemán Eberhard Schlotter. También está, de 1905, el denominado "Quijote del Centenario" con 689 láminas de J. Jiménez Aranda, así como la edición que ilustró Salvador Dalí y las de Antonio Saura o Mingote.

Todos estos ejemplares pueden ser consultados, comentados y explicados amablemente al visitante de la biblioteca por el personal de la misma.

Ma Carmen Martín Amat

Directora de la Biblioteca Hurtado de Mendoza de Órgiva

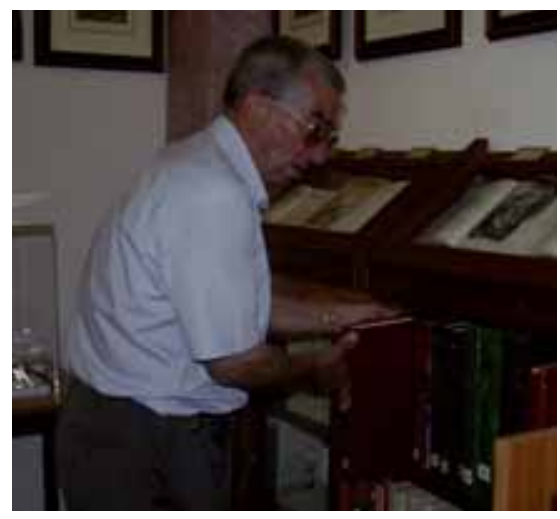

(1) Agustín Martín Zaragoza inició la colección sobre El Quijote en 1967 / Foto: RAFAel Vílchez Fernández

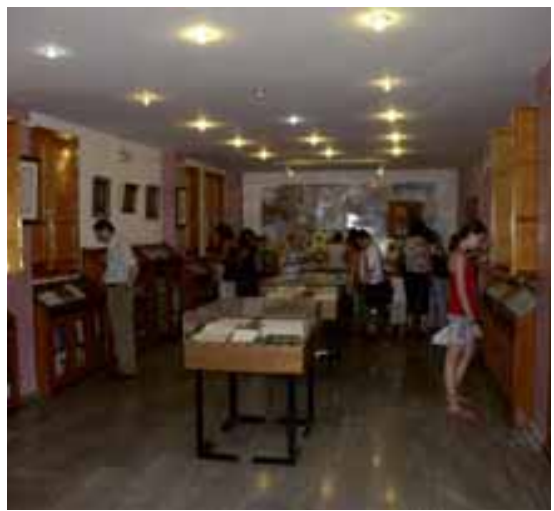

(1) Aula Cervantina Agustín Martín Zaragoza / Foto: José Antonio SÁnchez Jiménez. Fuente: Biblioteca MUNicipal HURTAdo de MENDOZA 